\section{The Loch Ness 'Monster'}

AT a general meeting of the Linnean Society of London, held on November 8, the Loch Ness 'monster' was for the first time discussed by a scientific society. Sir Edward Mountain gave an account of his endeavours to settle the creature's identity by employing twenty watchers distributed around the Loch under the supervision of Capt. Fraser. These watchers were supplied with cameras on loan from the Kodak Co. Ltd., and also with field glasses. During the first two weeks of last July, the creature was seen by the watchers twenty-one times. In September a film was taken by Capt. Fraser with a telephoto lens at a distance of about a mile from the creature; it was stated that the portion of the creature visible in the film had been estimated by the Kodak Co. to be about eight feet in length. The film was run through the projector several times and a discussion followed. The first impression of most members of the audience was probably that the movements of the creature shown on the film suggested those of a seal, but some of the speakers pointed out difficulties in the way. Commander R. T. Gould did not believe that the creature was a seal; he felt sure that the watchers would have readily recognised it as such. Further, he considered that it could not be a killer whale. Sir Sidney Harmer thought that until further evidence had been produced the verdict should be 'not proven'. $\mathrm{He}$ thought that the creature was not a cetacean, but would probably prove to be a seal. Mr. M. A. C. Hinton and Mr. F. C. Fraser felt certain that the creature was a seal, with which opinion Dr. Stanley Kemp disagreed; nor did he believe it to be a cetacean. Sir Arthur Smith Woodward, referring to the popular belief, said that it was hopeless to compare the creature with a Mesozoic reptile as no traces of these reptiles had been found in Tertiary rocks in any part of the world. Capt. J. G. Dollman was firmly convinced that the creature was an otter. The president (Dr. W. T. Calman) and Mr. A. J. Wilmott expressed doubts as to the size of the creature as estimated by the Kodak Company. Enlargements of some of the 'still' photographs taken by the watchers were also exhibited at the meeting.

\section{Electrical Disturbance of Radio Reception}

IT is well known that broadcast reception is often seriously interfered with by outside electrical disturbances over which the receiver has no control. A special committee was appointed by the Institution of Electrical Engineers a year ago to consider this problem, and evidence and assistance has been given to it by several official and unofficial organisations. At this early stage, it is clear that radio interference is widespread and constitutes a serious annoyance to the public. The committee finds that listeners and those who advise them have not yet done all that is possible on their receiving sets to mitigate some of the effects of interference. A memorandum has been prepared for the committee by the B.B.C. on the features of design and installation of radio sets which, when attended to, help to lessen, sometimes very appreciably, this trouble. The attention of those who supply radio sets is directed to this memorandum. On the Continent, where State regulations are favoured, little assistance is given to those listeners who do not take reasonable precautions against interference. Still, when the listener has done all he can, there is left a large amount of interference which can only be effectively corrected by suppression at the source. Interfering apparatus generally has a commutator motor, but mercury arc rectifiers and high-tension lines under certain conditions may cause trouble. As a first step towards assisting those manufacturers who desire to produce interference-free appliances, the committee has taken the initiative in the preparation of a specification with this end in view, and it is hoped with the co-operation of the British Standards Institution to issue a complete specification early next year.

THE committee is reluctant to be dogmatic on the subject of compulsory versus voluntary suppression of radio interference. It is not the tradition in England to make regulations until it is certain, first, that they are needed, and secondly, that they can be carried out effectively when made. There is at present much goodwill amongst all concerned, and readiness to help to rectify trouble when it is serious, but the committee believes that a threat, at the present time, to impose compulsory regulations might have the effect of retarding instead of forwarding progress. But when co-operation and goodwill have done their best, there may be a residuum of recalcitrant cases in which some form of compulsion will probably be desirable. Manufacturers are unwilling at the moment to express themselves definitely on the subject of compulsion. The extent of increase of price of appliances depends largely on the level of interference which is permissible. At a special international conference held in Paris last June, an approximate permissible level was suggested, but it was more tolerant than most countries would like to prescribe. It is agreed that, if hard and fast regulations are to be laid down immediately, a tolerant figure is inevitable.

\section{Beilby Memorial Awards}

THE administrators of the Beilby Memorial Fund, consisting of the officers of the Institute of Chemistry, the Society of Chemical Industry and the Institute of Metals, have awarded one hundred guineas each to Dr. W. Hume-Rothery, Royal Society Warren research fellow, and to Dr. E. A. Rudge. Dr. HumeRothery, who is thirty-five years of age, took first class honours in chemistry at Oxford, and then worked at metallography for three years at the Royal School of Mines under the direction of Sir Harold Carpenter, after which he returned to Oxford for independent research work. His published work includes a book on the electrical properties and theories of metals and alloys, papers on valency relations in alloy structures, and determinations of equilibrium diagrams of metallic systems. Dr. Hume-Rothery has introduced new conceptions and generalisations into the study of alloys, and has 